DOI: 10.14526/2070-4798-2020-15-1-29-35

\title{
Sexual dimorphism in young 11-12 year-old divers and swimmers
}

\author{
Evgeniya A. Raspopova*, Irina V. Chebotareva \\ Russian State University of Physical Culture, Sport, Youth and Tourism \\ Moscow, Russia \\ ORCID: oooo-ooo2-1129-4492, raspopova48@mail.ru* \\ ORCID: oooo-0oo2-7654-5221, iracheb2001@mail.ru
}

\begin{abstract}
Morphofunctional characteristics of athletes, who specialize in different kinds of sport are interesting for many scientists and it is reflected in their works. Special interest cause the characteristics of gender differences in the tempos of physical and biological development of athletes. They specialize in water kinds of sport. However, there were no works about sexual dimorphism comparison in 11-12 year-old children, who go in for diving and swimming. Materials. The article is about yearly growth of physical development indices in boys and girls. They go in for diving and swimming (sports schools of the Olympic reserve in Moscow). Research methods. Scientific literature analysis and summarizing, anthropometry, fractionation of body weight, methods of statistical data handling. Results. We revealed sexual differences in physical development, in proportions and body mass content in 11-12 year-old divers and swimmers. More distinct sexual dimorphism was revealed in the group of young 11-12 year-old swimmers according to the main indices of physical development, according to the index of body mass and body length ratio and fat component. Conclusion. The held research showed different degree of sexual dimorphism both in swimmers and divers at the age of 11-12.

Keywords: divers, swimmers, sexual dimorphism, physical development, body mass content, body proportions.
\end{abstract}

For citation: Evgeniya A. Raspopova*, Irina V. Chebotareva. Sexual dimorphism among young 11-12 year-old divers and swimmers. Russian Journal of Physical Education and Sport. 2020; 15(1): 25-30. DOI: 10.14526/2070-4798-2020-15-1-29-35

\section{INTRODUCTION}

Studying the peculiarities of male and female organism development in athletes of different specializations is one of the most important aspects of sports science $[1,2]$. Many well-known scientists studied the peculiarities of physical development of athletes in terms of age-related aspect [3,4 and others].

Nowadays there is no definite information concerning the methodology of training men and women. There are two different opinions concerning the problem of sexual dimorphism. One group of scientists offers to organize training women taking into account their biological characteristics and the other group of scientists insists that the training process should be organized in the same way as men [2].

In the theory of physical culture and sport the problem of sexual dimorphism is studied. This problem is based on gender differences of male and female sport. The main disadvantage of most modern research works in theory of physical culture is in the problem that the estimation of the received scientific results is held without taking into consideration sexual dimorphism. Only such kind of an approach would help to reveal objective reasons for the existing problems of female sport and reject out-of gender study of physical culture problems in general [2, 9-14].

In water kinds of sport, in our opinion, not enough attention is paid to this problem. The works by Timakova T.S. [5] reveal considerable differences between the type of constitution and puberty of boys and girls. Some works were dedicated to studying the influence of biological maturation tempos on the dynamics of sports achievements in swimmers and divers $[3,5,6,7,8]$. However, there were no works about sexual dimorphism study in these kinds of sport.

In this connection the aim of this research work was to reveal the peculiarities of sexual dimorphism demonstration in the tempos of physical development among 11-12 year-old divers 
and swimmers.

The objectives of the research:

1. To study sexual dimorphism in young 11-12 year-old swimmers and divers.

2. To reveal the main differences of sexual dimorphism in 11-12 year-old swimmers and divers.

\section{MATERIALS AND METHODS}

Physical development and constitution peculiarities study in young swimmers and divers was held by means of anthropometry method. The results were handled by means of mathematical statistics methods. We calculated the average indices - X, standard deviations - $\sigma$, and the validity of differences of the average indices according to Student t-test. The research was held on the basis of sports school of the Olympic reserve in Moscow in 2016-17.Young 11-13 year-old swimmers and divers took part in the research (20 people in each group).

\section{RESULTS AND DISCUSSION}

Sexual dimorphism study in young divers and swimmers showed that among 11 year-old girls, who go in for diving, body length indices are $2,3 \mathrm{~cm}$ higher, than among boys. The differences were not valid (table 1).

The indices of boys of the same age were higher than among girls, and the difference between them was $1,7 \mathrm{~cm}$.

At the age of 12 girls (divers and swimmers) have higher indices of body length than boys, among divers the difference is insignificant $(0,1 \mathrm{~cm})$, among swimmers- $6,1 \mathrm{~cm}$.

Yearly growth of body length in boys-divers was higher, than in girls for $2,2 \mathrm{~cm}$ (table 1) in swimmers yearly increases of body length among girls were higher that in boys (for 7,8 cm) (table 2).

According to body weight in divers and swimmers at the age of 11 the difference between boys and girls was the same and is $0,7 \mathrm{~kg}$. By the age of 12 the differences between the athletes of both genders increase. Divers boys surpass girls in weight for $3,2 \mathrm{~kg}$, in swimmers this index is higher in girls $(8,7 \mathrm{~kg})$. At the same time we revealed considerable differences of yearly weight increase in divers and swimmers. So yearly increases in boys-divers are 2,5 $\mathrm{kg}$ higher, than in girls and in swimmers yearly increases of girls were higher, than in boys for 9,4 $\mathrm{kg}$.

Table 1 - Comparative results of the main indices yearly increases in 11-12 year-old divers physical development

\begin{tabular}{|c|c|c|c|c|c|}
\hline \multirow{2}{*}{ Indices } & \multirow{2}{*}{$\begin{array}{c}\text { Age } \\
\text { (years) }\end{array}$} & Boys & Girls & \multirow{2}{*}{ P } & \\
\cline { 3 - 5 } & 11 & $136,2 \pm 4,0$ & $138,5 \pm 4,9$ & $-2,3$ & $>0,05$ \\
\hline \multirow{2}{*}{ Length of body (cm) } & 12 & $141,7 \pm 4,7$ & $141,8 \pm 4,7$ & $-0,1$ & $>0,05$ \\
\hline & $\Delta$ & 5,5 & 3,3 & 2,2 & \\
\hline Yearly increase & 11 & $31,5 \pm 2,6$ & $30,8 \pm 3,3$ & 0,7 & $>0,05$ \\
\hline \multirow{2}{*}{ Weight (kg) } & 12 & $35,5 \pm 4,3$ & $32,3 \pm 8,4$ & 3,2 & $>0,05$ \\
\hline Yearly increase & $\Delta$ & 4,0 & 1,5 & 2,5 & \\
\hline \multirow{2}{*}{ Chest volume (cm) } & 11 & $68,7 \pm 2,9$ & $67,1 \pm 3,7$ & 1,6 & $>0,05$ \\
\cline { 2 - 6 } & 12 & $71,7 \pm 3,7$ & $69,9 \pm 3,1$ & 1,8 & $>0,05$ \\
\hline Yearly increase & $\Delta$ & 3 & 2,8 & 0,2 & \\
\hline \multirow{2}{*}{ Broca Index (body length -} & 11 & 4,7 & 7,8 & $-3,1$ & \\
\cline { 2 - 5 } weight - 100) & 12 & 6,2 & 9,5 & $-3,3$ & \\
\hline Yearly increase & $\Delta$ & 1,5 & 1,7 & $-, 0,2$ & \\
\hline
\end{tabular}


Divers-boys surpass girls in chest volume for 1,6 cm, and girls-swimmers surpass boys for $0,4 \mathrm{~cm}$ (differences are invalid in both cases in case $\mathrm{p}>0,05)$.

By the age of 12 the differences according to this index in boys-divers increase insignificantly $(1,8 \mathrm{~cm})$, in swimmers there is considerable chest volume increase in girls for $10,8 \mathrm{~cm}$, at the same time the difference of chest volume in girls and boys is $9,9 \mathrm{~cm}$.

We revealed gender differences in yearly increases of chest volume index in the representatives of divers and swimmers. In divers the differences are insignificant. But swimmersgirls surpass boys in yearly increase for $9,5 \mathrm{~cm}$ $(\mathrm{p}<0,05)$.

Table 2 - Comparative results of yearly increases of the main physical development indices in 11-12 year-old swimmers

\begin{tabular}{|c|c|c|c|c|c|}
\hline \multirow{2}{*}{ Indices } & \multirow{2}{*}{$\begin{array}{c}\text { Age } \\
\text { (years) }\end{array}$} & Boys & Girls & \multirow[b]{2}{*}{$\Delta$} & \multirow{2}{*}{$\mathrm{P}$} \\
\hline & & $\mathrm{X} \pm \sigma$ & $\mathrm{X} \pm \sigma$ & & \\
\hline \multirow{2}{*}{ Body length (cm) } & 11 & $146,6 \pm 4,2$ & $144,9 \pm 1,6$ & 1,7 & $<0,05$ \\
\hline & 12 & $152,7 \pm 4,9$ & $158,8 \pm 4,8$ & $-6,1$ & $<0,01$ \\
\hline Yearly increase & $\Delta$ & 6,1 & 13,9 & $-7,8$ & \\
\hline \multirow{2}{*}{ Weight (kg) } & 11 & $35,3 \pm 1,9$ & $34,6 \pm 0,7$ & 0,7 & $>0,05$ \\
\hline & 12 & $37,5 \pm 4,1$ & $46,2 \pm 1,3$ & $-8,7$ & $<0,05$ \\
\hline Yearly increase & $\Delta$ & 2,2 & 11,6 & $-9,4$ & \\
\hline \multirow{2}{*}{ Chest volume $(\mathrm{cm})$} & 11 & $70,9 \pm 2,9$ & $71,3 \pm 1,2$ & $-0,4$ & $>0,05$ \\
\hline & 12 & $72,2 \pm 7,2$ & $82,1 \pm 4,8$ & $-9,9$ & $<0,05$ \\
\hline Yearly increase & $\Delta$ & 1,3 & 10,8 & $-9,5$ & \\
\hline \multirow{2}{*}{$\begin{array}{c}\text { Broca Index (body length - } \\
\text { weight }-100)\end{array}$} & 11 & 11,3 & 10,3 & 1,0 & \\
\hline & 12 & 15,2 & 12,6 & 2,6 & \\
\hline Yearly increase & $\Delta$ & 3,9 & 2,3 & 1,6 & \\
\hline
\end{tabular}

Broca Index in female divers is higher both of yearly increase of Broca Index was insignificantly at 11 and at 12 years-old, than in boys. In swimmers this index was higher than in boys. The difference higher $(0,2 \%)$ in female divers, and in swimmers it is higher in boys $(1,6 \%)$.

Table 3 - Comparative results of body proportions yearly changes in young 11-12 year-old divers, (in \%)

\begin{tabular}{|c|c|c|c|c|c|}
\hline \multirow{2}{*}{ Indices } & \multirow{2}{*}{$\begin{array}{c}\text { Age } \\
\text { (years) }\end{array}$} & Boys & Girls & \multirow{2}{*}{$\Delta$} & \multirow{2}{*}{$\mathrm{P}$} \\
\hline & & $\mathrm{X} \pm \sigma$ & $\mathrm{X} \pm \sigma$ & & \\
\hline \multirow{2}{*}{ Weight / body length } & 11 & $23,1 \pm 0,3$ & $22,2 \pm 0,3$ & 0,9 & $<0,05$ \\
\hline & 12 & $25,0 \pm 0,3$ & $22,7 \pm 0,3$ & 2,3 & $<0,01$ \\
\hline Yearly increase & $\Delta$ & 1,9 & 0,5 & 1,4 & \\
\hline \multirow{2}{*}{ Chest volume / body length } & 11 & $50,4 \pm 0,5$ & $48,4 \pm 0,4$ & 2,0 & $<0,05$ \\
\hline & 12 & $50,6 \pm 0,4$ & $49,3 \pm 0,3$ & 1,3 & $<0,05$ \\
\hline Yearly increase & $\Delta$ & 0,2 & 0,9 & $-0,7$ & \\
\hline \multirow{2}{*}{$\begin{array}{l}\text { Shoulders width / body } \\
\text { length }\end{array}$} & 11 & $21,0 \pm 0,3$ & $20,4 \pm 0,3$ & 0,6 & $<0,01$ \\
\hline & 12 & $22,1 \pm 0,5$ & $22,1 \pm 0,2$ & $\mathrm{O}$ & $>0,05$ \\
\hline Yearly increase & $\Delta$ & 1,1 & 1,7 & $-0,6$ & \\
\hline
\end{tabular}


Body proportions were studied according to the ratio of body weight, chest volume, shoulders width and body length of young 11-12 year-old divers and swimmers. The received results analysis show (tables 3 and 4) that at the age of 11 and 12 the ratio of body weight to body length in divers is higher in boys, than in girls. At the same time in boys yearly increase of this index is higher and the difference between boys and girls increases by the age of 12. Among swimmers gender differences at the age of 11 are insignificant and by the age of 12 there is considerable increase of this index among girls, which leads to valid differences at the age of 12.

The ratio of chest volume to body length in divers is higher in boys, than in girls. The situation in swimmers is different: at the age of 11 and 12 higher results have girls.

According to the ratio of shoulders width to body length there were differences at the age of 11. Among divers higher indices have boys among swimmers girls. But by the age of 12 these differences disappear.

Weight content analysis in divers and swimmers showed that girls have advantage in muscle component of body weight both at the age of 11 and 12 (tables 5 and 6). Yearly increases of muscle mass are higher in female divers (3,9\%), and in female swimmers they are lower $(1,9 \%)$. In boys-swimmers there is percentage of muscle mass decrease by the age of 12 (for $2,2 \%$ ), in divers there is positive dynamics. It is probably connected with the peculiarities of the divers training process, directed toward speed-power qualities development.

Speaking about bone component of body mass, it should be noted that swimmers have relatively lower indices, than divers. It is conditioned by the specificity of sports swimming. There light skeleton provides better hydrostatic and hydrodynamic qualities of an athlete.

Table 4 - Comparative results of body proportions yearly changes in 11-13 year-old swimmers (in \%)

\begin{tabular}{|c|c|c|c|c|c|}
\hline \multirow{2}{*}{ Indices } & \multirow{2}{*}{$\begin{array}{c}\text { Age } \\
\text { (years) }\end{array}$} & Boys & Gils & \multirow{2}{*}{$\Delta$} & \multirow{2}{*}{$\mathrm{P}$} \\
\cline { 3 - 5 } & $\mathbf{X} \pm \sigma$ & $\mathrm{X} \pm \sigma$ & & \\
\hline \multirow{2}{*}{ Weight / body length } & 11 & $24,1 \pm 0,3$ & $23,9 \pm 1,3$ & 0,2 & $>0,05$ \\
\cline { 2 - 5 } & 12 & $24,5 \pm 0,2$ & $29,1 \pm 1,2$ & $-4,6$ & $<0,05$ \\
\hline Yearly increase & $\Delta$ & 0,4 & 5,2 & $-4,8$ & \\
\hline \multirow{2}{*}{ Chest volume / body length } & 11 & $48,4 \pm 0,4$ & $49,2 \pm 0,5$ & $-0,8$ & $<0,05$ \\
\cline { 2 - 5 } & 12 & $47,3 \pm 0,5$ & $51,7 \pm 1,5$ & $-4,4$ & $<0,05$ \\
\hline Yearly increase & $\Delta$ & $-1,1$ & 2,5 & $-1,4$ & \\
\hline \multirow{2}{*}{ Shoulders width/ body } & 11 & $21,9 \pm 0,4$ & $22,6 \pm 1,4$ & $-0,7$ & $<0,05$ \\
\cline { 2 - 5 } length & 12 & $22,3 \pm 0,3$ & $22,3 \pm 1,3$ & 0 & $>0,05$ \\
\hline Yearly increase & $\Delta$ & 0,4 & $-0,3$ & 0,1 & \\
\hline
\end{tabular}

Studying percentage of fat component content in body weight showed that swimmers have the advantage over divers both at the age of 11 and
12. It is connected with the necessity to accumulate fat in order to have the opportunity to spend more time in water. 
Table 5 - Comparative results of weight content yearly changes in 11-13 year-old divers (\%)

\begin{tabular}{|c|c|c|c|c|c|}
\hline \multirow{2}{*}{ Indices } & \multirow{2}{*}{$\begin{array}{c}\text { Age } \\
\text { (years) }\end{array}$} & Boys & Girls & \multirow{2}{*}{$\Delta$} & $\mathrm{P}$ \\
\cline { 3 - 5 } & 11 & $45,6 \pm 3,9$ & $46,4 \pm 3,0$ & $-0,8$ & $>0,05$ \\
\hline \multirow{2}{*}{ Muscle mass \% } & 12 & $47,1 \pm 3,2$ & $50,3 \pm 6,6$ & $-3,2$ & $>0,05$ \\
\hline \multirow{2}{*}{ Yearly increase } & $\Delta$ & 1,5 & 3,9 & $-2,4$ & \\
\hline \multirow{2}{*}{ Bone mass \% } & 11 & $21,2 \pm 1,5$ & $20,9 \pm 1,1$ & 0,3 & $<0,05$ \\
\hline & 12 & $21,1 \pm 0,4$ & $21,2 \pm 3,6$ & $-0,1$ & $<0,05$ \\
\hline Yearly increase & $\Delta$ & $-0,1$ & 0,3 & 0,2 & \\
\hline \multirow{2}{*}{ Fat mass \% } & 11 & $4,3 \pm 1,9$ & $5,9 \pm 1,7$ & $-1,6$ & $<0,05$ \\
\hline & 12 & $10,6 \pm 0,5$ & $6,2 \pm 2,1$ & 4,4 & $<0,05$ \\
\hline Yearly increase & $\Delta$ & 6,3 & 0,3 & 6,0 & \\
\hline
\end{tabular}

Table 6 - Comparative results of weight content yearly changes in 11-12 year-old divers (\%)

\begin{tabular}{|c|c|c|c|c|c|}
\hline \multirow{2}{*}{ Indices } & \multirow{2}{*}{$\begin{array}{c}\text { Age } \\
\text { (years) }\end{array}$} & Boys & Girls & \multirow{2}{*}{$\Delta$} & $\mathrm{P}$ \\
\cline { 3 - 6 } & $\mathbf{1 1}$ & $46,1 \pm 3,7$ & $48,0 \pm 3,7$ & $-1,9$ & $>0,05$ \\
\hline \multirow{2}{*}{ Muscle mass \% } & 12 & $43,9 \pm 3,5$ & $49,9 \pm 3,5$ & $-6,0$ & $>0,05$ \\
\hline Yearly increase & $\Delta$ & $-2,2$ & 1,9 & $-0,3$ & \\
\hline \multirow{2}{*}{ Bone mass \% } & 11 & $19,2 \pm 1,6$ & $17,8 \pm 1,6$ & 1,4 & $>0,05$ \\
\cline { 2 - 5 } & 12 & $19,8 \pm 1,6$ & $17,9 \pm 1,6$ & 1,9 & $>0,05$ \\
\hline Yearly increase & $\Delta$ & 0,6 & 0,1 & 0,5 & \\
\hline \multirow{2}{*}{ Fat mass \% } & 11 & $17,4 \pm 5,6$ & $18,0 \pm 5,6$ & $-0,6$ & $<0,05$ \\
\cline { 2 - 5 } & 12 & $17,7 \pm 6,0$ & $21,8 \pm 6,0$ & $-4,1$ & $<0,05$ \\
\hline Yearly increase & $\Delta$ & 0,3 & 3,8 & $-3,5$ & \\
\hline
\end{tabular}

\section{CONCLUSION}

1. We revealed considerable gender differences of the main physical development indices yearly increases in divers and swimmers during the age period 11-12 years-old. In swimmers the difference of yearly body length indices increase in boys and girls was $7,8 \mathrm{~cm}$, in divers - 2,2 $\mathrm{cm}$., according to body weight in swimmers - 9,4 kg, in divers- 2,5kg, according to chest volume $-9,5 \mathrm{~cm}$ in swimmers and $0,2 \mathrm{~cm}$ in divers and according to Broca Index- 1,6and 0,2. Thus, sexual dimorphism at the age of 11-12 is vividly demonstrated in the group

\section{of swimmers.}

2. Body proportions study (the ratio of weight, chest volume and shoulders width to body length) in young divers and swimmers showed that yearly changes during the age period: 11-12 years old are insignificant in terms of chest volume and shoulders width to body length. According to the ratio of mass to body length gender differences are more vivid in swimmers.

3. It was stated that according to muscle component of weight at the age of 11 and 12 girls have the advantage (both divers and swimmers). However, sexual dimorphism is more distinct in 
divers. According to fat component more distinct gender differences are in swimmers.

\section{REFERENCES}

1. Iordanskaya F.A. Muzhchina I zhenchina $v$ sporte vysshih dostizhenij. Problemy polovogo dimorfizma: monografiya [Men and women in high achievements sport. Problems of sexual dimorphism: monograph]. Moscow: Soviet sport. 2012: 256 [In Russ.].

2. Kochetkova E.F., Oparina O.N. Peculiarities and problems of sexual dimorphism in sport. Sovremennye nauchnye issledovaniya I innovacii [Modern scientific research works and innovations]. 2014; 7. URL: http://web.snauka.ru/ issues/2014/07/35829 [In Russ.].

3. Statkyavichene B.V. Morphofunctional peculiarities of high class swimmers and their importance for selection and further sports development (women). Candidate's thesis. Moscow: Russian University of Physical Culture and Sport. 1986: 24 .

4. Timakova T.S. The main problems and directions of creating the integral system of talented athletes selection. Otbor, control' I prognozirovanie $v$ sportivnoj trenirovke. K.: KSIPC. 1990: 16-27 [In Russ.].

5. Raspopova E.A., Chebotareva I.V. Physical development of young 11-13 year-old swimmers and divers. Pedagogiko-psihologicheskie I medico-biologicheskie problemy fizicheskoj kul'tury I sporta = Russian Journal of Physical Education and Sport. 2019; 14(1): 33-37. DOI: 10.14526/2070-4798-2019-14-1-33-37 [In Russ., In Engl.]

6. Raspopova E.A., Chebotareva I.V. Physical development of 11-12 year-old girls, who go in for swimming and diving. Materials of the $1^{\text {st }}$ International Volga Economics and Humanitarian sciences and sport conference. September, 24-25, 2019. Kazan. 2019. URL: http://www.atlantispress. $\mathrm{com} / \mathrm{php} / \mathrm{pub}$.php?publication=ficehs -19 .

$$
\text { 7. Raspopova E.A., Panasyuk T.V., }
$$

Shovgenya N.E. Gender characteristics of a longterm training of divers from springboard and diving tower. Sovremennyj Olimpijskij sport I sport dlya vseh: materialy XIII Mezhdunarodnogo nauchnogo kongressa [Modern Olympic Sport and sport for everybody: materials of the XIII International scientific congress]. Alma-Ata. 2009; 2: 267-270.

8. Raspopova E.A., Postolnik Yu.A. Comparative analysis of dominant motives inducing students fromdifferent higher educational establishments to go in for physical culture lessons. Pedagogiko-psihologicheskie $i$ medicobiologicheskie problemy fizicheskoj kul'tury $i$ sporta $=$ The Russian Journal of Physical Education and Sport. 2018; 13(1): 125-132. DOI: 10/14526/01_2018_291 [in Russ., in Engl.].

9. Bishop D. Warm up II: Performance changes following active warm up and how to structure the warm up. Sports Medicine. 2003; 33: 483-498.

10. Bradley P.S., Olsen P.D., Portas M.D. The effect of static, ballistic, and proprioceptive neuromuscular facilitation stretching on vertical jump performance. Journal of Strength and Conditioning Research. 2007; 21: 223-226.

11. Brandenburg J., Pitney W., Luebbers P., Veera A., Czajka A. Time course of changes in vertical-jumping ability after static stretching. International journal of Sports Physiology and Performance. 2007; 2: 170-181.

12. Faigenbaum A.D., Bellucci M., Bernieri A., Bakker A., Hoorens K. Acute effects of different warm-up protocols on fitness performance in children. Journal of Strength and Conditioning Research. 2005; 271: R1251-R1255.

13. McNeal J., Sands W. Acute static stretching reduces lower extremity power in trained children. Paediatric Exercise Sciences. 2003; 15: 139-145.

14. Nelson A.G., Driscoll N.M., Landin D.K., Young M.A., Schexnayder I.C. Acute effects of passive muscle stretching on sprint performance. Journal of Sports Sciences. 2005; 23: 449-455.

\section{Submitted: 03.02.2020}

\section{Author's information:}

Evgeniya A. Raspopova-Doctor of Pedagogics, Professor, Russian State University of PhysicalCulture, Sport, Youth and Tourism, 105122, Russia, Moscow, Sirenevyi blvd., House 4, e-mail: raspopova48@ $\underline{\text { mail.ru }}$

Irina V. Chebotareva - Candidate of Pedagogics, Associate Professor, Russian State University of Physical Culture, Sport, Youth and Tourism, 105122, Russia, Moscow, Sirenevyi blvd., House 4, e-mail: iracheb2001@mail.ru 